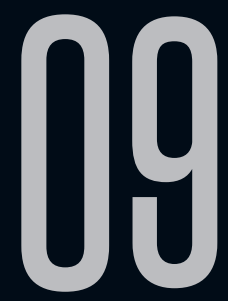

\title{
CINEMA RETROFUTURISTA E STEAMPUNK: POSSÍVEIS ORIGENS DE UM SUBGÊNERO LITERÁRIO
}

Jayme Soares Chaves (UERJ)

Recebido em 11 fev 2018. Jayme Soares Chaves é Doutorando em Literatura Aprovado em 24 abr 2018. Comparada pela UERJ e Mestre em Teoria da Literatura e Literatura Comparada. Autor do artigo "Em '1985', Anthony Burgess anteviu a submissão do Ocidente ao Islã", para o Jornal Opção, de Goiânia, em homenagem ao centenário do escritor, publicado em 27 de fevereiro de 2017. Áreas de interesse: ficção científica, literatura fantástica, cinema, teatro e ópera. Ministrou o curso "A ucronia e seus desdobramentos: história, ficção e literatura fantástica" na Casa de Leitura Dirce Côrtes Riedel em abril de 2017. Lattes: http://lattes.cnpq.br/3583953060597388. E-mail: jayme.chaves@gmail.com

Resumo: O artigo procura examinar o fenômeno do subgênero steampunk na literatura de ficção científica contemporânea, rastreando suas origens e analisando suas definições. O steampunk trabalha com projeções contrafactuais do passado vitoriano, criando ambientações retrofuturistas para narrar suas histórias. A partir de indícios levantados por pesquisadores sobre a marcante influência cinematográfica sobre este subgênero, em especial as releituras feitas por Hollywood dos scientific romances britânicos e das voyages extraordinaires 
de Júlio Verne, procurou-se demonstrar a afinidade da arte cinematográfica, desde seus primórdios, com esse universo ficcional, e a possibilidade de se determinar sua origem nas experiências de tradução visual deste universo.

Palavras-chave: Steampunk; Retrofuturismo; Júlio Verne.

Abstract: The article seeks to examine the phenomenon of the subgenre steampunk in contemporary science fiction literature, tracing its origins and analyzing its definitions. Steampunk works with counterfactual visions of the Victorian past, creating retrofuturistic ambiances to tell their stories. Based on indications raised by researchers about the remarkable cinematographic influence on this subgenre, in particular the re-readings made by Hollywood of British scientific romances and the voyages extraordinaires of Jules Verne, it was tried to demonstrate the affinity of the cinematographic art, from its beginnings, with this fictional universe, and the possibility of determining its origin in the filmic translation experiences of this universe.

Keywords: Steampunk; Retrofuturism; Jules Verne.

Em 1987 a palavra steampunk foi usada pela primeira vez para classificar os romances e contos escritos entre 1978 e 1987 por três autores de ficção científica (FC) californianos: James P. Blaylock, K.W. Jeter e Tim Powers. Estes textos chamaram atenção pela semelhança temática: Morlock Night (1979) e Infernal Devices: A Mad Victorian Fantasy (1987), de K. W. Jeter, The Ape-Box Affair (1978), The Idol's Eye (1984) e Homunculus (1986), de James P. Blaylock, e The Anubis Gates (1983), de Tim Powers. Todos eles apresentavam enredos ambientados na Inglaterra vitoriana, uma coexistência entre tecnologia e ocultismo, e a interação entre personagens históricos, fictícios e tomados de empréstimo dos 
clássicos scientific romances do século XIX. Em abril de 1987, K. W. Jeter escreveu uma carta para a revista Locus, respondendo ao crítico Faren Miller, onde ironizava a tendência cyberpunk na FC dos anos 1980, ao mesmo tempo que ressaltava a semelhança temática entre suas obras e as de Blaylock e Powers:

Pessoalmente eu acho que as fantasias vitorianas serão a próxima grande tendência, contanto que possamos chegar a um termo adequado para Powers, Blaylock e eu. Algo baseado na tecnologia própria da época. Como steampunks, talvez... (VANDERMEER, Jeff e CHAMBERS, S.J, 2011, p.48)

Evidentemente, Jeter ironizava. O subgênero da FC que ele parodiava, o cyberpunk, era considerado a grande tendência da época, com seus enredos ambientados em um futuro não tão distante, dominado pela informática e pela cibernética, em um contexto social de miséria e degradação. Ao classificar as "fantasias vitorianas" que ele e seus colegas vinham escrevendo como steampunk, operando um deslocamento do presente computadorizado (cyber) para o passado da Revolução Industrial (steam), Jeter cunhou uma palavra monstruosa, deselegante, cujo destino natural seria cair no esquecimento após sobreviver o tempo suficiente para provocar gargalhadas.

Mas não foi o que aconteceu. Como frequentemente ocorre, uma ironia ou um termo pejorativo termina por ser aceito e assumido para designar determinada prática artística ${ }^{1}$. E quando o escritor Paul DiFilippo publica, em 1995, The Steampunk Trilogy, o termo foi assumido em uma obra literária pela primeira vez. 1 Existe o caso clássico do Impressionismo. O termo foi utilizado por Louis Leroy em 1874 para menosprezar o quadro de Claude Monet, Impression, soleil levant, e acabou sendo adotado para rotular todo um movimento artístico. 
Em 1999, a minissérie de histórias em quadrinhos The League of Extraordinary Gentlemen, escrita por Alan Moore e desenhada por Kevin O'Neill, parodiava a ideia de equipes de super-heróis apresentando uma aventura protagonizada por um grupo formado por personagens bem conhecidos dos scientific romances e das voyages extraordinaires do século XIX: Allan Quatermain (de As minas do Rei Salomão, de H. Rider Haggard), o Homem Invisível (de H.G. Wells), Dr. Jekyll (de Robert Louis Stevenson), Mina Harker (de Drácula, de Bram Stoker), e o Capitão Nemo (de 20.000 léguas submarinas, de Júlio Verne). Apesar de seus autores não classificarem seu trabalho como steampunk, a associação foi imediata. E no ano 2000, que marca o início do grande boom do subgênero em várias mídias, outra minissérie em quadrinhos, publicada em doze números, intitulava-se precisamente Steampunk. O salto decisivo para a popularização definitiva do subgênero foi a adaptação cinematográfica da League de Moore e O’Neill em 2003, dirigida por Stephen Norrington. Embora bastante infiel e empobrecida, sem nada da ironia e do cinismo que caracterizava a série original, ajudou a dar visibilidade ao gênero, para o bem ou para o mal. $E$, como acontece todas as vezes que um novo gênero ou subgênero é criado, várias hipóteses são formuladas, não apenas na tentativa de rastrear seus antecedentes e precursores, mas também na tentativa de defini-lo e encontrar as razões de sua existência.

O texto de Peter Nichols para o verbete de 1995 em The Encyclopedia of Science Fiction descreve o steampunk sucintamente como "o moderno subgênero cujos eventos de fiç̧ão científica ocorrem em um contexto do século XIX." Steffen Hantke considera-o um fenômeno, ainda que periférico, pertencente ao 
neovitorianismo, "este terreno popular e lucrativo (...) que é em si parte da tradição maior e mais antiga do romance histórico". Duplamente periférico, pois a "localização deste conjunto de textos é realmente marginal em relação ao mainstream literário, em parte porque sua lealdade principal não é para com as tradições realistas convencionais, mas para com a ficção científica". Triplamente periférico, pois como Hantke observou, o steampunk "constitui um caso especial entre as histórias alternativas, um subgênero da ficção científica que postula um evento fictício de vastas consequências no passado e extrapola a partir deste evento um presente ou futuro fictícios, embora historicamente contingentes" (HANTKE, 1999, p.245). No entanto, nem sempre os exemplos desta literatura se encaixam em uma definição abrangente o bastante para dar conta de todas as suas variantes. Existem histórias ambientadas em uma época vitoriana alternativa, existem histórias ambientadas em um futuro que preservou características da época vitoriana, e existem histórias ambientadas em um universo paralelo que apresenta características similares à época vitoriana. O que estas narrativas poderiam ter em comum seria uma ênfase na tecnologia, seja uma tecnologia do passado que extrapola as suas limitações históricas, seja uma tecnologia futura, cujo desenvolvimento em um período histórico passado cria um ponto de divergência que altera a cronologia tal como a conhecemos, ou ainda um hibridismo de tecnologias futuras e passadas em um mundo secundário, ou universo alternativo. Diz Hantke:

Em parte devido à sua íntima ligação com a ficção científica, o steampunk se concentra na tecnologia como o fator crucial para a compreensão e interpretação do Vitorianismo. Ao adotar o nome 
steampunk, ou seja, em escolhendo a máquina a vapor como o ícone mais adequado do passado para descrever a si mesmo, ele torna a tecnologia o seu principal foco. Sendo o mundo contemporâneo altamente tecnológico, qualquer passado em que ele pudesse ver-se refletido deveria compartilhar, ou melhor, deveria ser construído para compartilhar, a sua agenda cultural. (1999, p.247)

Mas nem mesmo a ênfase na tecnologia poderia ser um denominador comum que possibilite uma definição mais precisa. Os casos mais notórios são justamente os romances seminais de Jeter, Blaylock e Powers. Morlock Night, o primeiro romance de Jeter identificado com o subgênero, é uma continuação de The Time Machine, de H.G. Wells, misturada a elementos de fantasia medieval arturiana; os contos e romances de Blaylock protagonizados por Langdon St. Ives são pastiches humorísticos de scientific romances; e The Anubis Gates, de Powers, é uma história de viagem no tempo onde o protagonista vê-se envolvido em uma conspiração conduzida por ocultistas egípcios que pretendem restaurar o culto aos antigos deuses e destruir o Império Britânico. Estes exemplos se adaptam melhor à expressão "fantasias vitorianas" do que aos posteriores significados de steampunk, como uma modalidade estrita de ficção científica. Por isso, Hantke demonstra certa prudência quando diz que, "considerando a rapidez com que o steampunk se fragmentou em uma desconcertante variedade de estilos, os críticos fariam melhor se considerassem suas próprias definições como hipóteses de trabalho" (p.246).

Nichols (1995) ressalta que "em essência, o steampunk é um fenômeno norte-americano, muitas vezes ambientado em uma 
Londres que é encarada ao mesmo tempo como profundamente estranha e intimamente familiar, uma espécie de corpo estranho incrustado no subconsciente dos EUA" (1995, n/p. Nichols observa que o denominador comum em Jeter, Blaylock e Powers é o fato de que, nestes livros, "a Londres dickensiana é, em si mesma, um dos personagens principais". A referência a Charles Dickens não é gratuita. Para alguns escritores de FC, a Londres vitoriana correspondia a um momento decisivo na história,

um momento particularmente relevante para a própria ficção científica. Era uma cidade de indústria, ciência, tecnologia, comércio e, acima de tudo, finanças, onde o mundo moderno estava nascendo, e uma claustrofóbica cidade de pesadelo, onde os custos desse crescimento foram registrados em sujeira e imundície. Dickens - o grande escritor steampunk original - sabia de tudo isso. (NICHOLS, 1995, n/p)

De qualquer forma, seja encarando o steampunk como gênero ou, como quer Mike Perschon, como uma "estética que pode ser aplicada a muitos gêneros, subgêneros e gêneros híbridos" (2012, p.12), o olhar para o passado, nostálgico, crítico, irreverente ou desconstrutor, um passado geralmente compreendido entre meados do século XIX e início do século XX, é a nota dominante. Se a Londres de Dickens serviu de contexto primordial, outras referências logo iriam juntar-se ao catálogo de lugares-comuns do steampunk. Embora a ênfase na tecnologia não seja um elemento constitutivo obrigatório, quando ela existe este olhar passadista volta-se para as origens da ficção científica, para o produto cultural resultante do progresso tecnológico e científico da Revolução Industrial, e para a crítica a esse mesmo progresso. A tecnologia do 
vapor, o passado, encontra-se, então, com a tecnologia do futuro, do futuro do pretérito.

Mas atravessando o Canal da Mancha, talvez pelo túnel imaginado por Georges Méliès em seu filme proto-steampunk de 1907, Tunnel sous la manche ou Le cauchemar franco-anglais, encontraremos um outro corpo incrustado no subconsciente norte-americano. Pois se Dickens e Wells forneceram aos autores steampunk a imagem de uma distopia, Júlio Verne, na França, forneceu a imagem da viagem extraordinária, feita por meio de veículos extraordinários, modernas odisseias do homem industrial. Quando a influência de Dickens é minimizada a partir do momento em que o steampunk transcende a sua primitiva condição de fantasia vitoriana, a obra de Júlio Verne passa a impregnar o imaginário dos escritores e artistas que trabalham com esta estética. Mas - e esse é o ponto defendido por esse artigo - não somente o Júlio Verne das obras originais. Existe, principalmente, a influência de um Júlio Verne transfigurado e reinventado pelo cinema. Essa reinvenção, bem como suas emulações, transpostas para outros universos ficcionais, desempenhou um papel crucial na formação do imaginário desses escritores que, informados pelas lentes das câmeras cinematográficas que modificaram ou distorceram as obras originais, construíram uma visão muito particular dessas obras e seu contexto.

Isso não escapou a atenção de alguns estudiosos. Perschon, e outros, ressaltaram a importância do universo verniano no steampunk. Mas, e isso é fundamental, por universo verniano eles entendem os textos e também as imagens por eles influenciadas: 
Enquanto ostextos escritos não podemserignorados como antepassados literários do steampunk, a proliferação de adaptações cinematográficas de romances científicos vitorianos após o sucesso de 20.000 Legues Under the Sea da Disney, em 1954, parece ser uma razão mais provável para sua popularidade. O desejo nostálgico semelhante ao que Fredric Jameson fala em relação a Star Wars está ostensivamente em jogo para aqueles cuja experiência nas matinês de sábado incluíram os 20 anos entre 1951 e 1971, quando os filmes baseados em Verne foram realizados regularmente, junto a numerosas adaptações de obras de H.G. Wells, Edgar Rice Burroughs, e Sir Arthur Conan Doyle. (PERSCHON, 2012, p.20)

A influência desses filmes, como diz Perschon (p.22), tem sido subestimada pela maioria dos comentadores. O cinema, como outros meios audiovisuais, exerce talvez maior influência sobre a literatura fantástica contemporânea do que seus antecedentes literários, as grandes obras do passado. O marco inicial desta nova realidade da literatura de entretenimento pode ser encontrado neste momento específico da indústria do cinema, quando suas câmeras apontam para o passado da ficção científica. Portanto, o propósito de nosso trabalho é tentar rastrear as origens deste subgênero, aceitando a premissa de que o imaginário dos artistas e escritores que se dedicam ao steampunk foi moldado pela interpretação cinematográfica dos scientific romances e voyages extraordinaires do século XIX.

O alvorecer do século $X X$ assistiu às primeiras manifestações de uma nova forma de entretenimento popular, então conhecida como cinematógrafo. Por isso, nunca é demasiado observar 
que, desde as primeiras experiências, duas vertentes surgiram e se desenvolveram paralelamente, configurando a gramática fundamental com a qual o cinema trabalharia posteriormente: a realista e documental, objetivo inicial de Louis Lumiére, e a fantástica, ficcional e não-realista, incluindo aquilo que viria a ser conhecido como ficção científica. E foi justamente Lumiére quem produziu os primeiros exemplares de ambas as vertentes, quando em 1895 filmou La Sortie des Usines e, em 1897, aquele que será considerado o primeiro filme de ficção científica da história: Charcuterie mécanique, que em quarenta e quatro segundos mostra uma curiosa máquina movida a manivela, onde um porco vivo é colocado dentro de um compartimento à direita e transformado automaticamente em salsichas, que são retiradas de outro compartimento, à esquerda. Desprovido de enredo, o curta-metragem apenas faz uma demonstração de um dispositivo mecânico inexistente, cujo efeito era similar aos clássicos truques de mágica, populares nos teatros da época: uma coisa transforma-se em outra. Também no mesmo ano, o mágico profissional George Méliès já havia iniciado sua carreira de cineasta desde que, em 1895, atendendo a um convite de Antoine Lumiére, pai dos irmãos Louis e Auguste, deixou o seu escritório no Theatre Robert-Houdin para comparecer a uma sessão do Cinematógrafo Lumiére, instalado no Salão Indiano do Grand Café, em Paris. Quando começa a fazer filmes, descobre por acaso, graças a um problema mecânico no aparelho, o truque de fazer coisas desaparecerem ou transformarem-se em outras. Em 1897, emprega conscientemente essa técnica pela primeira vez no filme Escamotage d'une dame chez Robert- 
Houdin (TOULET, 1988, p.13). Nascia, a partir deste momento, o cinema fantástico e seus efeitos especiais.

O cinema de Méliès derivava da féerie, espetáculo cênico de caráter fantástico, que surgiu na França após a Revolução. Katherine Singer Kovács descreve esta forma teatral de um modo que poderia, sem dúvida, descrever o próprio cinema de Méliès:

Os enredos das féeries eram geralmente adaptados de contos de fadas, em que criaturas sobrenaturais intervinham na vida dos homens. Estas criaturas usavam talismãs mágicos para efetuar a metamorfose repentina de pessoas ou coisas, e a rápida substituição de um cenário por outro diante dos olhos do espectador.

As aparições, desaparecimentos, e transformações, que eram práticas normais nas peças de conto de fadas, encantaram e surpreenderam as audiências que não estavam familiarizadas com a maquinaria teatral que facilitava estas mudanças. Para elas, as ações que testemunhavam eram uma espécie de magia. Gautier comparava-as a sonhos. (KOVÁCS, 1976, p.1-2)

A féerie e seus derivados, como a pièce à grand spectacle ${ }^{2}$ e o cinema de Méliès, sempre estiveram, de uma forma ou de outra, ligados à obra de Júlio Verne. Em 1875, um ano após a estreia da adaptação teatral de $A$ volta ao mundo em oitenta dias, Jacques Offenbach estreou sua ópera-féerie La Voyage dans la Lune, vagamente baseada no romance original de Verne e com algumas cenas inspiradas em Viagem ao centro da terra, sem autorização do autor e sem o reconhecimento dos créditos.

2 Entretenimento teatral extravagante, que após o desastre da Guerra Franco Prussiana, tornou-se o divertimento escapista por excelência da burguesia parisiense. 
A imprensa apontou o que Verne chamou de "empréstimos" (ANGELIER, 2012, s/p), mas, aparentemente, plagiadores e plagiado terminaram por chegar a algum acordo, visto que dois anos depois Verne colaboraria com Offenbach em outra opereta baseada em seus escritos: Le Docteur $O x$.

Méliès, nascido em 1861, cresceu sob a influência tanto da féerie parisiense quanto das Voyages Extraordinaires vernianas. Quando no liceu, "como todos os rapazes de sua idade, lia Júlio Verne abertamente e Baudelaire em segredo." (PUISIEUX, 1984, p.25). Provavelmente entrou em contato com Edgar Allan Poe via Baudelaire, como o próprio Verne havia feito. Seu filme mais famoso, Le voyage dans la Lune (1902), se não foi o primeiro exemplo de ficção científica do cinema, é sem dúvida um marco na história do cinema mundial cujo roteiro também antecipa uma prática comum da literatura steampunk: é inspirado tanto em Verne, texto e ilustrações, quanto na ópera de Offenbach e ainda no romance First Men in the Moon, de H.G. Wells ${ }^{3}$. Méliès ainda adaptaria outros romances e peças de Verne, como Voyage à travers l'impossible (1904), 20000 lieues sous les mers (1907), muito livremente inspirada no romance homônimo, e À la conquête du pôle (1912), considerado por alguns críticos a sua obra-prima, e no qual trabalha temas retirados de quatro romances de Verne: Robur, o conquistador, $O$ senhor do mundo, Capitão Hatteras e $A$ esfinge dos gelos. O fato de filmes desta importância estarem ligados, de um modo ou de outro, ao nome de Verne, não pode ser ignorado nesta nossa tentativa de rastrear a evolução do imaginário oriundo

30 romance de Wells havia sido publicado em francês em 1901, não sendo impossível, portanto, que Méliès o tenha lido. 
das Voyages Extraordinaires, para o estabelecimento de um corpus transmidiático decisivo na fundamentação do steampunk. Verne "informa" Méliès. É impossível, ao assistir as cenas da trajetória do projétil no espaço em Le voyage dans la Lune, não rememorar as ilustrações de Émile-Antoine Bayard e Alphonse de Neuville para o romance original. Não é por acaso que um dos fundadores dos Cahiers du Cinema, Joseph-Marie Lo Duca, em breve nota sobre Méliès no décimo número, observa que quando o cineasta, em seus filmes, trocava o "fantástico de laboratório pelo fantástico geográfico ou sideral" (1952, p.52), Júlio Verne era uma espécie de leitmotiv. Existe algo de familiar entre as duas obras, e ao olhar de perto as gravuras do romance e os desenhos de Méliès, o ar familiar se acentua e percebemos haver ali "mais do que um encontro". E não apenas em Le voyage dans la Lune. Mesmo a sua nada fiel versão das aventuras do Capitão Nemo, filmada em 1907, que do romance original guarda apenas o título e o submarino, a referência visual é sempre a arte de Édouard Riou e Alphonse de Neuville, ilustradores da primeira edição.

É curioso que, na mesma nota, Lo Duca rememore uma conversa pessoal com o cineasta, na qual este teria declarado que a única coisa em comum entre o seu filme e o livro é a Lua, mas que Verne não a havia inventado. E Lo Duca conclui que o "orgulho amável de Méliès" não poderia escamotear todos os "empréstimos" feitos ao universo de Verne (1952, p.52-53).

De 1902 até o início da década de 1930, quando Hugo Gernsback consolida o gênero da ficção científica através de publicações como Amazing Stories, foram produzidas vinte adaptações de romances de Júlio Verne para o cinema. De 1895, 
ano da realização da Charcuterie mécanique, até a mesma data, oitenta e cinco filmes que poderiam ser classificados como ficção científica foram realizados. Vários, se não explicitamente baseados em Verne, faziam uso de elementos de seu universo. É fácil perceber o leitmotiv de Júlio Verne repetindo-se tanto nos textos que estavam sendo publicados como nos filmes: aeroplanos, dirigíveis, submarinos, viagens à Lua e outros planetas, cometas que se chocam contra a Terra, etc. E não apenas Verne: o alvorecer da arte cinematográfica coincidiu com o estabelecimento de um corpus textual apropriado para os desafios técnicos que esta arte encontrava no intuito de maravilhar os espectadores. Este corpus, posteriormente, se tornará fundamental nas referências do steampunk.

Outros expoentes do fantástico vitoriano também começaram a ser adaptados para o cinema ainda nos primórdios. Wells aparece no cinema pela primeira vez em 1909 com um filme baseado em The Invisible Man. Em 1900 foi produzida a primeira adaptação das aventuras de Sherlock Holmes, Sherlock Holmes Baffled, dando início à longa série de aparições do detetive criado por Arthur Conan Doyle na película. Edgar Allan Poe estreou nas telas em 1908, e de modo bastante curioso: atrelado ao célebre personagem de Doyle. Trata-se de um exercício transficcional, caro aos escritores steampunk, baseado em Murders in the Rue Morgue, intitulado Sherlock Holmes in the Great Murder Mistery. Em 1899, H. Rider Haggard apareceu nas telas com uma adaptação de She; Bram Stoker teve o seu Drácula adaptado na Hungria ${ }^{4}$ em 1921, 
antes que F.W. Murnau realizasse o seu famoso Nosferatu um ano depois; o Frankenstein de Mary Shelley, considerado por alguns críticos o primeiro romance de ficção científica, surge no cinema pelas mãos de Thomas Edison em 1910; Edgar Rice Burroughs viu o seu Tarzan filmado em 1917 com The Lad and the Lion. Até o início da década de 30, foram produzidos cerca de treze filmes baseados em escritos de Wells, oitenta e nove filmes baseados em escritos de Conan Doyle, vinte e seis em Poe, dezenove em Haggard, dez em Burroughs, cinco em Shelley e dois em Stoker. Essa estatística demonstra, além da popularidade infatigável de Sherlock Holmes, que Verne só é superado por Poe em número de adaptações cinematográficas, o que não foi suficiente para abalar sua reputação como "pai da ficção científica". No caso de Burroughs, Stoker e Shelley, pode surpreender o pequeno número de filmes, mas há que se considerar o fato de que o auge dos filmes com Tarzan se deu entre as décadas de 1930 e 1970, e que após as aparições de Drácula e do Monstro de Frankenstein pela Universal Pictures em 1930, o período de maior popularidade destes personagens foi nas décadas de 1960 e 1970.

Entre 1902 e 1954, ano da produção de Twenty Thousand Leagues Under the Sea pela Walt Disney Productions, foram realizadas trinta adaptações cinematográficas das Voyages Extraordinaires. Dentre estas, a obra mais popular entre os produtores é Michel Strogoff, com sete versões, seguida por Vinte mil léguas submarinas, com cinco, e A ilha misteriosa, com três. O imaginário produzido por histórias de viagens extraordinárias, especulações científicas, mistério e terror escritas a partir da segunda metade do século XIX continuava a povoar a mente de artistas e público através do cinema. 
Os primeiros filmes a explorar o material produzido pelos escritores especulativos das eras Vitoriana e Eduardiana enfrentaram o problema de tornar críveis, aos olhos do espectador, as maravilhas técnicas que seus enredos retratavam. Assim, aquilo que era originalmente apenas especulativo e ganhava existência potencial apenas na letra do autor, ou ainda nas ilustrações que porventura a acompanhassem, no cinema necessitava avançar um passo em direção a uma existência concreta. Em outras palavras, o espectador precisava ver em movimento aquilo que estava sendo descrito ou mostrado. Não foi por acaso que os primeiros filmes baseados na obra de Júlio Verne tiveram de se defrontar com o problema de tornar reais, aos olhos do espectador, a materialização de suas utopias tecnológicas. Em 1916, após as experiências de Méliès, a primeira grande adaptação de um romance de Verne chegou às telas, trazendo uma significativa contribuição para a evolução das técnicas de filmagem e dos efeitos especiais: Twenty Thousand Leagues Under the Sea, dirigido por Stuart Paton, foi o primeiro longa-metragem de ficção a realizar filmagens submarinas, através de um engenhoso dispositivo desenvolvido pelo Capitão Charles Williamson e seus filhos John Ernest e George Maurice.

$\mathrm{O}$ roteiro do filme de Paton se baseava tanto em Vinte mil léguas submarinas quanto em A ilha misteriosa. E foi justamente este segundo romance que inspirou um filme de 1929, The Mysterious Island, dirigido por Lucien Hubbard, e que, apesar de pouco conhecido e pouco apreciado, será peça importante no futuro desenvolvimento de uma arqueologia da estética steampunk. E, assim como o filme de Paton, também foi uma espécie de laboratório para futuras técnicas empregadas no cinema. 
O que torna este filme interessante para o espectador interessado ou familiarizado com as tendências mais recentes da ficção científica, como o retrofuturismo ou o steampunk, é que seu roteiro foi inspirado exclusivamente por um único trecho do romance original, ignorando o resto. O trecho, que consta no capítulo XVI da terceira parte de A ilha misteriosa, é a narrativa das origens do Capitão Nemo, príncipe indiano cujo nome verdadeiro era Dakkar, filho do rajá do Bundelkund, território então independente do domínio inglês. Apesar de educado na Europa e aparentemente levar uma vida ociosa, transitando pela alta sociedade internacional, acalentava secretamente o sonho de libertar a nação indiana do jugo britânico. Principal mentor, na ucronia de Verne, da Revolta dos Sipaios de 1857, sua família foi massacrada e sua cabeça posta a prêmio. Homem de ciência, milionário, construiu o submarino Nautilus e afastou-se da vida em terra, passando a desbravar as profundezas do oceano e apoiar as nações que lutavam por independência.

Mas dizemos que o roteiro foi apenas "inspirado", pois as mudanças foram radicais. Em vez da Índia, temos o fictício reino eslavo de Hetvia; Dakkar tem André como prenome e é um Conde; em sua ilha-fortaleza, uma espécie de estado paralelo, constrói não apenas um único submarino, mas dois, e nenhum deles se chama Nautilus. O problema político é um golpe de estado liderado pelo Barão Falon, que procura apropriar-se dos submarinos e utilizá-los como armas de guerra. As cenas da invasão da ilha pelos hussardos leais a Falon remetem ao visual construtivista do cinema soviético em voga na época. O início do filme descreve Hetvia como um país "turbulento como as ondas que se quebram em suas costas 
rochosas". As imagens das ondas fundem-se com imagens de camponeses em revolta, um truque de montagem típico do cinema produzido na antiga URSS, embora realizado de modo menos sofisticado. Em sequência, durante a fuga de Dakkar em um dos submarinos, temos a descoberta de um reino nas profundezas, habitado por estranhos antropoides aquáticos, polvos gigantes e répteis pré-históricos. Após a derrota dos revoltosos, Dakkar, ferido de morte e desgostoso com o provável uso maléfico de suas invenções, destrói seus laboratórios e embarca sozinho em um dos submarinos, desaparecendo sob as águas.

O interessante no enredo é que, entre outras coisas, o filme cria uma versão alternativa da história original, prática recorrente da literatura steampunk, e também uma versão alternativa do mapamúndi do século XIX. E, por último, antecipa outra prática recorrente da literatura e do cinema de entretenimento contemporâneos: abolindo todo o enredo do romance e tomando como base apenas o pequeno trecho onde as origens de Nemo são narradas, cria uma história pregressa, um prequel da história original. Pois não fica claro, ao final da película, se Dakkar de fato morreu. Pode-se especular sua futura ressurreição como Capitão Nemo, que rompe com a humanidade e passa a habitar as profundezas dos mares, aliás como acontece de fato na história de Verne.

O interesse pela ficção científica do século XIX perdurou no cinema da década de 1950. Após roteirizar o seu próprio livro em Things to Come, dirigido por William Cameron Menzies em 1936, e ver toda uma série produzida pela Universal nas décadas de 30 e 40 a partir de The Invisible Man, H.G. Wells retorna às telas em 1953, com The War of the Worlds, dirigido por Byron Haskin e 
produzida por George Pal, em versão modernizada, ambientada na própria época de sua produção para aproveitar o clima de paranoia induzido pela Guerra Fria, responsável por uma série de filmes sobre invasões alienígenas. Mas um ano depois Hollywood redescobriria a Era Vitoriana do romance científico em seu contexto próprio, ainda que não isento, obviamente, de um olhar contemporâneo. Esta redescoberta terá como marco inicial o filme que é considerado uma das melhores versões para o cinema de uma obra de Júlio Verne e a melhor versão de Vinte mil léguas submarinas já filmada. A partir da realização deste filme, a representação cinematográfica do passado vitoriano e eduardiano idealizada por determinada leitura do scientific romance e da voyage extraordinaire vai tornar-se praticamente um subgênero no cinema. De 1954 a 1978, podemos observar um fluxo constante de filmes com temática verniana e wellsiana, ou mesmo de filmes que evocam o contexto histórico, científico e tecnológico em que estas obras foram gestadas. Tratase de um fenômeno na história do cinema que ainda não chamou a atenção dos estudiosos, com exceção de um ou outro comentário esporádico, normalmente sobre este ou aquele filme, mas que não comporta uma visão global do problema e nem abarca a totalidade do fenômeno. É justamente neste fluxo de filmes que sugerimos encontrar as origens do steampunk.

O que existe em comum entre todos estes filmes, para além dos períodos históricos enfocados e para além dos gêneros nos quais eles são comumente classificados, como comédia, aventura, fantasia ou FC, é a presença daquilo que Arthur B. Evans chama de "utopia veicular". Segundo Evans, ao contrário da maioria das utopias e distopias criadas pelos escritores de ficção especulativa, 
que, de um modo ou de outro, prestam tributo à tradição iniciada por Sir Thomas More em 1518, as verdadeiras utopias presentes nos romances de Júlio Verne são utopias móveis, "veiculares", ainda que alguns traços das utopias tradicionais possam ser encontrados em determinadas histórias.

Um importante novo paradigma na história da especulação utópica nasceu no século 19 , na Europa, durante este período de mudança social dramática que hoje chamamos de Revolução Industrial. Este novo paradigma utópico era o conceito de mobilidade ilimitada. Na França, como as ferrovias continuaram a se multiplicar por toda a área rural e navios a vapor cruzavam os mares em direção a portos cada vez mais distantes, o foco utópico da burguesia francesa do Segundo Império e da Terceira República rapidamente começou a mudar com os tempos. A tradicional utopia do "lugar nenhum" foi logo substituída por um potencial "em qualquer lugar", o cenário pastoral pelo industrial; a ética pessoal pelo expansionismo competitivo; e, talvez tão importante, os fins utópicos pelos meios utópicos. A melhoria dos meios de transporte tornou-se um corolário a priori para todo o "Progresso" real. O maior sonho? Veículos que poderiam maximizar a velocidade (maximizando assim o comércio, lucro e lazer), minimizando o tempo desperdiçado no trânsito; veículos que poderiam aumentar o conforto pessoal, eliminando o tédio; veículos que poderiam exalar poder, eficiência e praticidade e ainda permanecerem elegantes para os olhos e calmantes para os sentidos; veículos que poderiam "ir onde nenhum homem jamais esteve", proporcionando um antídoto caseiro ao contínuo dépaysement de ambientes estrangeiros. $\mathrm{E}$, acima de tudo, veículos que poderiam ser a propriedade privada exclusiva 
de seus proprietários que, sozinhos, decidiriam o seu destino e utilização final. Tal era o novo ideal: facilidade de circulação em um mundo em movimento. "Mobilis in mobili", como o Capitão Nemo do Nautilus diria. (EVANS, 1999, p.99)

Esta passagem do "lugar nenhum" para o "qualquer lugar" é realizada pela concepção de veículos "hiperbólicos", "máquinas de sonho", que Evans vê como sendo as verdadeiras utopias vernianas, ainda que alguns romances descrevam formas utópicas tradicionais, como a Ilha Lincoln de A ilha misteriosa e Franceville de Os 500 milhões da Begun, ou distopias, como o Stahlstadt do mesmo livro, ou a Paris de 1961 em Paris no século XX. Os veículos idealizados por Verne possuem a característica de serem indevassáveis em seu aspecto exterior. Isolados do ambiente externo, são providos em seu interior de todo o conforto material e espiritual almejados pela burguesia do século XIX:

Confortavelmente isolados do exterior, esses veículos também são suntuosamente equipados no interior: luxuosa mobília vitoriana, obras de arte, sala de jantar, uma biblioteca bem abastecida, para não mencionar itens indispensáveis como serviçais dedicados e uma fonte quase inesgotável de provisões para proporcionar o máximo de conforto físico, emocional e intelectual. O interior luxuoso do Nautilus de Nemo é um exemplo óbvio, como o são os mais compactos, mas igualmente confortáveis aposentos a bordo da sonda lunar de Barbicane, ou "vagão-projétil", como o autor preferiu chamá-lo. (EVANS, 1999, p.101)

O mundo exterior, para estes privilegiados habitantes de utopias móveis, é sempre um espetáculo a que se assiste, segura e 
confortavelmente, através de alguma espécie de janela que funciona como um observatório-cinematógrafo. Evans observa que "estas janelas servem para demarcar a fronteira entre o 'nós' e o 'eles', entre a segura familiaridade do conhecido e a implícita ameaça do 'Outro', seja ele os elementos, nativos hostis ou perigosas fauna e flora" (1999, p.102). Em A casa a vapor, as janelas laterais do Gigante de Aço, formidável paquiderme mecânico movido a vapor que cruza o subcontinente indiano conduzindo luxuosos vagões tripulados por ingleses, e que proporciona aos viajantes um passeio pela geografia e pela história do Raj, paisagens vislumbradas nas gravuras de Léon Benett. Podemos perceber o movimento especular provocado pela relação imagem-janela-gravura, onde o viajante dos "mundos conhecidos e desconhecidos" é o leitor. Isso mostra, e Evans não deixou de o notar, que a fixação por estruturas de "clausura e conforto" (BARTHES, 2009) é o próprio coração do projeto pedagógico de Verne e de seu editor Pierre-Jules Hetzel:

Mas se o objetivo social desta série de romances foi a transmissão de um corpo fixo de conhecimentos, o meio didático para este fim foi a viagem ficcional. E é aqui, como mencionado, que encontramos a verdadeira inovação de Verne, acrescentando uma dimensão inteiramente nova para os elementos utópicos tradicionais de clausura, autonomia e conforto: as utopias veiculares de Verne não são apenas autossuficientes e acolhedoras, elas também são extremamente móveis transportando rapidamente seus passageiros para locais em constante mudança e proporcionandoIhes continuamente novas, exóticas paisagens para contemplar e aprender. Além disso, elas também servem na maioria das vezes como cabinets de travail ambulantes, suprindo as necessidades não 
só do corpo e do espírito, mas também do intelecto - fornecendo aos cientistas vernianos uma plataforma inigualável para o seu trabalho contínuo de mapear o universo e descobrir os mais profundos segredos da Natureza. (EVANS, 1999, p.105)

E por último, e não menos importante, as "máquinas de sonho" vernianas também são retratadas como "objets d'art tecnológicos":

Eles atuam como trampolins fictícios para a imaginação do leitor aventurar-se não apenas em novas dimensões do espaço físico, mas também em novos padrões de apreciação estética. O dispositivo mecânico em si é visto como um objeto de Beleza, levando consigo os seus próprios critérios de forma e função: sutileza de design, precisão de movimentos, força de material, retidão de linha, amplitude de efeito, etc. A função poética destes veículos é ainda mais enfatizada pelo fato de que eles nunca são retratados como entidades econômicas (como na obra de Zola, por exemplo): eles não criam empregos, nem os substituem; eles não produzem "mais-valia", no sentido marxista; eles não fabricam matéria-prima; eles não são comprados e vendidos. Eles servem apenas para tornar possível o impossível, o fantástico, real, e o improvável, crível. A sua principal razão de ser é criar para o leitor um espaço interior imaginário para explorar, ao lado de heróis da ficção de Verne, as fronteiras ultraperiféricas do real. (EVANS, 1999, p.106)

Vamos agora demonstrar, em nossa viagem pelas obras cinematográficas que, de 1954 a 1978, evocaram o grande momento histórico das "utopias veiculares" e foram responsáveis pela construção do universo mental dos artistas e escritores steampunk, o estranho fenômeno da duplicação regressiva destas utopias. Pois 
se em uma primeira leitura pareceria evidente que as máquinas extraordinárias de Verne não poderiam conservar o seu caráter utópico cem anos após a sua concepção, em uma segunda leitura seria igualmente evidente que os desejos (ou ilusões) de isolamento, conforto, autonomia, mobilidade e beleza permanecem contínuos e imutáveis. E o marco inicial da atualização, no século $X X$, da utopia veicular verniana foi, como já dissemos, em 1954. Este ano funciona como uma espécie de máquina do tempo, onde o viajante se desloca do presente para um passado alternativo, ucrônico, passado reestruturado pela percepção tecnológica do presente. Senão, vejamos: em 21 de janeiro de 1954, o primeiro submarino movido a energia atômica, o USS Nautilus (SSN-571), foi batizado e lançado nas águas do rio Thames, em Connecticut; em 23 de dezembro do mesmo ano, estreou nos cinemas dos Estados Unidos uma produção dos estúdios Walt Disney, Twenty Thousands Leagues Under the Sea, baseada no livro homônimo de Júlio Verne, dirigida por Richard Fleischer, e que apresentava para as plateias o mais famoso design do Nautilus do Capitão Nemo, uma releitura retrofuturista da ideia original de Verne e Alphonse de Neuville. Esta imagem, obra do artista Harper Goff, permanece indelevelmente impressa na memória coletiva, ao ponto do crítico Brian Taves declarar que nos dias de hoje, "a leitura de todo entusiasta de Verne das obras originais é obrigada a estar interligada com a visão dos filmes. $O$ 'texto' verniano não é mais simplesmente os seus romances, mas o acúmulo de impressões adquiridas através de várias versões nas artes do espetáculo" (TAVES, 1996, p.205 - grifo nosso).

Goff era um talentoso desenhista de produção que já havia trabalhado para a Warner Brothers em vários filmes importantes 
da história do cinema, como Midsummer's Nights Dream de Max Reinhardt; Captain Blood, The Charge of the Light Brigade e Casablanca, todos dirigidos por Michael Curtiz; Sergeant York, de Howard Hawks, entre outros. Em 1952, tendo abandonado o estúdio desde o final da década de 1940 para trabalhar como freelancer e como ilustrador de periódicos, o acaso fez com que ele encontrasse Walt Disney em uma loja de ferromodelismo em Londres. Sendo um grande admirador do trabalho de Goff, Disney convidou-o para trabalhar no projeto da Disneylândia, e mais tarde incumbiu-o da tarefa de assistir alguns filmes feitos no laboratório marinho do Instituto de Tecnologia da Califórnia para a série de documentários sobre a vida selvagem, que Disney então produzia. Enquanto desenhava storyboards a partir dos filmes, Goff começou a esboçar cenas inspiradas pelas memórias de suas leituras do livro de Júlio Verne na infância e do filme de 1916, assistido aos seis anos de idade. Disney viu os esboços e foi o bastante para reacender uma velha ideia: filmar Twenty Thousands Leagues Under the Sea. Seria a primeira produção americana em liveaction dos estúdios Disney ${ }^{5}$, uma superprodução em Technicolor e CinemaScope, com James Mason interpretando o Capitão Nemo e Kirk Douglas como Ned Land.

O primeiro problema enfrentado pela produção foi a construção do roteiro a partir do romance. O diretor Richard Fleischer estava consciente de que a problemática tradução norte-americana, resumida e simplificada, não continha uma na Inglaterra. O primeiro foi Treasure Island, de 1950, baseado em Stevenson. Em seguida vieram The Story of Robin Hood and His Merry Men (1952), The Sword and the Rose e Rob Roy: The Highland Rogue (1953). 
história concreta, apenas uma série de incidentes. Então, ele e o roteirista Earl Fenton tiveram de fazer o que Fleischer chamou de "trabalho de detetive" para preencher as lacunas, principalmente em relação ao caráter de Nemo. Duas modificações significativas foram feitas: o anarquista revolucionário de origem nobre que rompe todos os laços com a humanidade da história de Verne foi transformado, em primeiro lugar, em um pacifista, ansioso por dividir seus segredos e conhecimentos com o resto da humanidade, caso esta renuncie as suas inclinações guerreiras e opressivas. A década de 1950 vivia sob o terror de uma nova guerra com armas nucleares, e o fantasma do fim dos tempos assombrava as mentes do público e dos artistas que se dedicavam à ficção especulativa. Em segundo lugar, Nemo é um justiceiro que, tendo sido ele mesmo um escravo no passado, luta com todas as suas forças contra a prática do tráfico de escravos.

O segundo problema enfrentado na adaptação do livro foi a transformação de um romance científico de propósitos educativos em algo que mantivesse o interesse da plateia ao longo da projeção. "No romance, Aronnax, Conseil e Ned simplesmente agem como observadores", explicava Fleischer. "Você não pode fazer isso por muito tempo no cinema". Então Fenton chegou à conclusão de que o filme deveria ser sobre o clássico tema da fuga da prisão, em si mesmo um subgênero cinematográfico. Aronnax deseja permanecer para conhecer cada vez mais as maravilhas do oceano e os segredos de Nemo; Conseil e Ned Land querem fugir do Nautilus, e passam todo o tempo de duração do filme criando estratégias e planos de fuga. Três incidentes no romance, considerados pelo diretor e pelo roteirista como "os mais memoráveis", foram aproveitados: o 
funeral submarino, o ataque dos canibais de Papua e o combate contra a lula gigante. Tendo por estabelecido o fato de que, graças às traduções medíocres, a maioria do público nunca havia lido o romance original com a devida atenção, Fleischer e Fenton apostaram na aceitação da história que estava sendo proposta. E de fato, como ressalta Fleischer, "a história que é hoje conhecida pela maioria dos jovens é aquela que inventamos para a tela" (FRAZIER; HATHORNE, 1984, s/p).

Mas havia ainda um terceiro desafio, e este é fundamental para entendermos a natureza da ficção retrofuturista como um todo, e do steampunk em particular. Fleischer assim o resume:

Tivemos que modernizar a história, a fim de criar uma sensação de coisas futuras. O desafio da nossa história era manter a sensação de ficção científica em algo que já não era mais ficção científica. Tivemos de pegar um objeto familiar o submarino - e torná-lo um objeto de espanto e fantasia. Nosso objetivo foi colocar o público em uma posição de nunca ter visto ou ouvido falar de um submarino antes, e conduzi-lo através das maravilhas deste artefato pela primeira vez. (FRAZIER; HATHORNE, 1984, s/p)

Nenhuma descrição da literatura retrofuturista e ucrônica, da qual o steampunk faz parte, poderia ser mais precisa: devolver para a ficção científica o que já não é mais ficção científica; tornar o familiar, fantástico e espantoso; o conhecido, desconhecido. O que nos leva diretamente à concepção do design do submarino. Além de ser movido a energia atômica, como o seu homônimo da marinha americana, de modo a atualizar o caráter premonitório ou "visão profética" do romance, o Nautilus de Harper Goff foi modificado em 
relação ao modelo original a partir de suas próprias características, tal como descritas no livro de Verne:

Goff acreditava que a história de Verne, sem as maravilhas mecânicas do submarino, teria sido simplesmente outro conto padrão de aventuras. Embora a história tenha sido criada em meados do século XIX, o Nautilus tinha que fazer coisas que eram impossíveis mesmo para o submarino moderno. Por exemplo, ele tinha que arremeter contra navios a uma velocidade tremenda, sem sofrer danos irreparáveis em seu casco. Portanto, tinha que ser extremamente pouco convencional em termos de design e operação.

O primeiro desafio de Goff foi projetar um submarino que tivesse a aparência de um monstro marinho. Lembra Goff: "O livro diz que o Nautilus foi confundido pelos observadores com um monstro marinho aterrorizante. Eu sempre pensei que os temíveis tubarões e crocodilos pareciam bastante mortais dentro da água, então eu baseei o meu projeto em suas características físicas. 0 corpo aerodinâmico do submarino, barbatana dorsal e cauda proeminente simulavam os traços do tubarão. Os pesados padrões de rebite sobre as placas de superfície representavam a pele áspera do crocodilo, enquanto as janelas frontais e os holofotes na parte superior representavam seus olhos ameaçadores. (FRAZIER; HATHORNE, $1984, s / p)$

Goff e Disney tiveram o seu momento de discordância. Com as ilustrações de Riou e Neuville em mente, Disney mostrou a Goff um tubo de alumínio para charutos, dizendo ser este o modelo de Nautilus que tinha em mente. Disney queria um visual futurista. Goff discordou, enumerando uma série de argumentos, desde as 
rudes condições em que Nemo teria construído o submarino em sua base secreta, até o padrão de chapas de aço rebitadas utilizado na construção naval da época. Uma importante mudança que os roteiristas fizeram na história pregressa de Nemo era o fato do submarino ter sido construído a partir de sobras e destroços resgatados de navios naufragados. Isso impossibilitaria a fabricação de um objeto fusiforme, de superfície lisa, conforme a concepção de Disney, além de não oferecer nenhum estímulo visual para as plateias. Goff não cedeu e sua concepção acabou prevalecendo. E ele estava certo. Retomando o conceito de Evans, a ameaçadora indevassabilidade do Nautilus de Goff permite o perfeito isolamento e mobilidade ao cidadão da utopia veicular, que encontra em seu interior o espaço ideal para exercer sua autonomia e seu gosto pela beleza. Goff compreendeu que, ao tornar a aparência do Nautilus mais terrível, seu interior, por contraste, deveria ser ainda mais suntuoso do que sugerem as descrições de Verne e as gravuras de Riou e Neuville. Persuadido de que nada seria tão atraente quanto "a combinação de ferro áspero e elegantes objetos de luxo", Goff projetou o interior do Nautilus como uma combinação entre máquinas futuristas acionadas por meio de pistões e um elegante mobiliário estilo império, que se adequava à estrutura tubular de ferro que o circundava.

Em Verne, Nemo é um homem rico. As partes que constituem seu submarino são encomendadas separadamente nas melhores indústrias do mundo, e montadas em sua base secreta, que ao término do trabalho é destruída. As obras de arte, os livros e o órgão de tubos que adornam o grande salão do submarino foram comprados e colecionados nos dias opulentos de sua vida terrestre. 
O Nemo de Fleischer e Fenton é um ex-escravo que constrói a sua utopia veicular com restos e destroços coletados de naufrágios, inclusive os livros, as obras de arte e o órgão de tubos. O Nautilus, como toda utopia veicular verniana, é uma obra de arte em si mesma. Mas o Nautilus de Harper Goff vai mais além: seja em sua forma externa, terrível, ameaçadora, de uma beleza apavorante, seja pelo ecletismo dos elementos que compõe a sua forma interna, é uma obra de arte moderna. O Nautilus de Goff/Nemo é um produto de bricolagem, de um do-it-yourself, de uma "estética do lixo", como diria Andy Wharol. Em outras palavras, mais do que somente uma estética punk, é uma verdadeira estética steampunk.

O sucesso do filme serviu não apenas para atualizar e perpetuar o imaginário relacionado à Verne para as plateias da Era Atômica, um público que tinha a sua disposição uma literatura e uma cinematografia de ficção científica em franco desenvolvimento, graças aos esforços pioneiros de Hetzel, e Hugo Gernsback. Serviu também para catapultar toda uma série de filmes que lançavam um olhar retroativo para a grande época das utopias veiculares. Apreciemos panoramicamente este mosaico.

Em 1956, Michael Todd produz Around the World in Eighty Days, dirigido por Michael Anderson, filmado em Todd-AO, sistema widescreen que concorria com o CinemaScope. O filme, transpondo para as telas a estrutura da féerie parisiense e da musical extravaganza americana, estilos de espetáculo teatral para os quais o romance de Verne já havia sido anteriormente adaptado, é uma espécie de apoteose das utopias veiculares, onde Phileas Fogg, apenas para ganhar uma aposta, investe toda a sua fortuna para exercer plenamente os seus ideais de conforto, autonomia, 
isolamento, mobilidade e beleza. Um dos grandes achados do filme é a conexão que, em sua ouverture, é feita entre o passado e o futuro do cinema: o filme inicia-se com La Voyage dans la Lune, de Méliès, que surge diminuto em seu aspecto de filmagem 1.33:1 na imensidão de uma sala de cinema equipada com tela widescreen, para em seguida, através de um efeito de montagem, conectar a cena da viagem espacial com imagens reais feitas por satélite, momento em que a janela de projeção se abre para o espetacular 2.20:1 do sistema Todd-AO.

Em 1958, Byron Haskin dirige From Earth to the Moon, retratando o "vagão-projétil", funcional por fora, elegante por dentro. Assim como no caso de Twenty Leagues Under the Sea, o enredo original foi modificado para explorar as ânsias da Era Atômica: Impey Barbicane inventa uma nova fonte de energia, a qual chama de Power $X$, no intuito de fabricar novas e poderosas armas de guerra. A viagem à Lua, neste contexto, é apenas um teste para suas reais motivações.

No mesmo ano, o cineasta tcheco Karel Zeman realizará uma das grandes homenagens cinematográficas tanto ao universo de Júlio Verne quanto ao de Georges Méliès: Vynález zkázy, ou The Deadly Invention, ou ainda The Fabulous World of Jules Verne. Trata-se de uma adaptação de Face au Drapeau, com elementos de Vingt milieus e Robur. Um dos marcos do sempre notável cinema de animação tcheco, este filme é uma criativa colagem das mais variadas técnicas, antigas e modernas, para reproduzir o sense of wonder que caracterizava a era do romance científico. Nas palavras de Pauline Kael, 
O filme cria a atmosfera dos livros de Júlio Verne, que está associada na mente dos leitores com as gravuras de Bennet e Riou; foi concebido para se parecer com este mundo-que-nunca-foi ganhando vida, e Zeman preserva a antiga característica de faz de conta pelo uso inteligente de fracas linhas horizontais sobre algumas das imagens. Ele sustenta o tom vitoriano, com o seu prazer na magia da ciência, que faz Verne parecer tão ludicamente arcaico. (1991, p.179)

Zeman recupera para o cinema o universo das ilustrações das Voyages Extraordinaires, dando prosseguimento ao que já havia sido iniciado por Méliès e por Eduard Pentslin. Ele ainda voltaria ao universo de Verne em mais três filmes. Baron Prášil, de 1961, ou The Fabulous Baron Munchausen, onde as técnicas anteriormente empregadas são ainda mais depuradas, adicionando com maestria o uso da cor e tendo Gustave Doré como principal referência visual, além do uso de extravagante transficcionalidade, método comum na estética steampunk, para estruturar o roteiro: um astronauta desembarca na Lua e descobre os destroços do "vagão-projétil" verniano. Na Lua, ele encontra-se com o Barão de Munchausen, Cyrano de Bergerac e os três astronautas do romance de Verne. O filme seguinte, de 1967, é Ukradená vzducholod, ou The Stolen Airship, livremente baseado em Deux ans de vacances e L'T̂le Mystérieuse. E por último, Na kometě, ou On the Comet, de 1970, baseado em Hector Servadac.

Voltando na cronologia, após esse apanhado da obra verniana de Karel Zeman, em 1959 foi produzido o filme Journey to the Center of the Earth; em 1960, aquele que pode ser considerado outro marco na atualização das utopias veiculares, ainda que 
desta vez não se trate de Júlio Verne: The Time Machine, dirigido por George Pal, que já havia visitado o universo de H.G. Wells como produtor de The War of the Worlds em 1953. Ao contrário do filme anterior, Pal não transpôs a história original para o século $X X$. Realizou um filme de época (pelo menos no início, antes do protagonista iniciar sua viagem temporal), com preocupações diferentes das que mobilizaram a equipe de Twenty Thousands Leagues Under the Sea. Ao contrário de um submarino, uma máquina do tempo permanece, e talvez sempre permaneça, um artefato do reino da ficção científica. George Pal rememorou a questão pragmaticamente:

Nós modernizamos The War of the Worlds porque os discos voadores eram um lugar-comum naquela época. Em The Time Machine não o fizemos porque tivemos um problema diferente. Ali o problema era convencer o público de que a máquina do tempo era real. Então nós a colocamos no passado, na virada do século, e mostramos incidentes que o público sabia que haviam acontecido, como as mudanças na moda feminina, a Primeira Guerra Mundial, a Segunda Guerra Mundial, etc. Até este ponto as pessoas acreditavam, então prosseguiram acreditando que havia coisas no futuro como pequenas pessoas loiras na superfície e monstros albinos abaixo.

(http://colemanzone.com/Time_Machine_Project/ pal_Time\%20Machine.htm)

O design da Máquina, obra do próprio Pal e do diretor de arte William Ferrari, se tornou outro ícone cinematográfico, talvez não tão influente quanto o Nautilus de Harper Goff, mas igualmente memorável, com sua elegância vitoriana e um certo charme 
antiquado. A construção do modelo também seguiu os padrões da "estética do lixo", do do-it-yourself: uma cadeira de barbeiro Berninghaus do fim do século XIX foi adaptada dentro de uma estrutura metálica que lembrava um trenó puxado por cavalos, reminiscência de infância de Pal. No prefácio à sua tradução de The Time Machine, Bráulio Tavares explica a diferença entre a Máquina de Wells e os veículos de Verne:

A máquina de Wells, contudo, é de uma natureza literária diferente do submarino do Capitão Nemo ou do balão do dr. Ferguson. Sua descrição lembra menos um veículo do que um objeto decorativo ou artístico, como uma caixinha de música ou um ovo Fabergé. A adaptação cinematográfica de George Pal (1960) recriou essa máquina (com design de William Ferrari) transformando-a numa espécie de trenó metálico, com um painel de controle, um assento e, num detalhe ausente do livro, um enorme disco rotatório por trás do assento, disco que se põe a girar quando a máquina é acionada. É um dos mais belos artefatos do cinema steampunk e reforça o sentido art noveau, ornamental e puramente estético do engenho imaginado por Wells. Não é um maquinismo utilitário, é uma obra de arte com peças mecânicas. (TAVARES Apud WELLS, 2010, p.8-9)

Talvez a Máquina do Tempo deva ser melhor classificada como uma "distopia veicular". Sua mobilidade é limitada àquilo que Wells nos habituou a considerar como sendo o Tempo, ou seja, a quarta dimensão; ela não é confortável, não fornece autonomia e não protege o viajante de perigos externos. É apenas bela. Mas de uma beleza desconfortável, pois sua função é antecipar ao seu usuário as tragédias vindouras, o futuro desalentador. 
O ano de 1961, segundo Brian Taves (1996, p.227), foi o auge das adaptações de Verne para o cinema, com cinco filmes, sem contar as produções televisivas: Master of the World, baseado em Robur, estrelado por Vincent Price, Valley of the Dragons, adaptação de Hector Servadac, Le triomphe de Michel Strogoff, o já mencionado Baron Prášil e Mysterious Island, mais uma versão do romance, desta vez bastante infiel, mas acrescida de estranhas e fantásticas criaturas concebidas pelo mestre da animação stop-motion Ray Harryhausen. Um detalhe interessante é o design do Nautilus neste filme, explicitamente influenciado por Harper Goff.

Em 1962, mais duas adaptações vernianas: Five Weeks in a Baloon, e o retorno dos estúdios Disney a Júlio Verne: In Search of the Castaways, baseado em Os filhos do capitão Grant. O primeiro segue a tradição verniana das utopias veiculares, mostrando ao público um estilizado balão de listras brancas e vermelhas, que sustenta uma gôndola estilo império cuja proa é adornada com a cabeça de um unicórnio. Se o filme não é memorável, a imagem deste balão permaneceu.

Em 1964, uma adaptação de H.G. Wells retorna às telas com First Men in the Moon, novamente com Ray Harryhausen à frente dos efeitos especiais. O design da espaçonave esférica revestida de chapas de um metal antigravitacional chamado "cavorita", que permite a ascensão à Lua, evoca o Nautilus de Goff com seu padrão de aço rebitado. Seu interior, apesar de compacto, é elegante e acolchoado. Um fino artefato vitoriano.

Dois filmes de 1965, duas comédias, uma produção britânica e uma produção americana, evocaram o fim da era em que os romances 
científicos foram gestados, embora não tenham se baseado em nenhum deles. Estrearam nos cinemas quase simultaneamente: Those Magnificent Men in Their Flying Machines or How I Flew from London to Paris in 25 hours and 11 minutes, dirigido por Ken Annakin, e The Great Race, de Blake Edwards. Após a realização de quatorze filmes em dez anos, cujo ponto de convergência é a evocação das maravilhas tecnológicas tal como foram imaginadas e descritas nos romances científicos e nas viagens extraordinárias, é impossível não olhar hoje para estas comédias sem incluí-las no mesmo fenômeno. Ambas são impressionantes e apoteóticas representações dos primórdios da Era das Máquinas: The Great Race, com suas intermináveis sucessões de balões, dirigíveis, foguetes, automóveis, aeroplanos, locomotivas e submarinos, procura emular as antigas comédias de Mack Sennet da era silenciosa para contar a história de uma corrida automobilística de Nova York à Paris (inspirada em uma famosa competição que ocorreu em 1908 e que seguiu o mesmo trajeto), onde os competidores tentam suplantar um ao outro por meio de trapaças e curiosos dispositivos mecânicos. Those Magnificent Men, ambientada em 1910, também retrata uma corrida, mas uma corrida de aeroplanos entre Londres e Paris. Vinte réplicas de biplanos, triplanos e monoplanos foram construídas, sendo que seis podiam voar. O filme é estruturado de forma semelhante a Around the World in Eighty Days: foi também filmado em Todd-AO e em sua ouverture apresenta velhos filmes silenciosos que documentavam as primeiras e canhestras tentativas de fazer um aeroplano voar. Ambos os filmes possuem hoje o status de cult, apesar de The Great Race não ter sido um sucesso na época, ao contrário de Those Magnificent Men, cujo sucesso gerou em 1967 
uma adaptação cômica de De la Terre à la Lune, Jules Verne's Rocket to the Moon, também conhecido como Those Fantastic Flying Fools. O próprio Ken Annakin filmou em 1969 uma sequência de seu filme, Monte Carlo or Bust! ou Those Daring Young Men in Their Jaunty Jalopies, desta vez inspirado no histórico rally de Monte Carlo que aconteceu em 1911.

Neste meio tempo, filmes como Chitty Chitty Bang Bang, The Lost Continent (1968) e Captain Nemo and the Underwater City (1969) eram produzidos. Em 1970 Billy Wider dirige sua brilhante ficção contrafactual envolvendo o detetive criado por Conan Doyle, The Private Life of Sherlock Holmes, onde espiões do Kaiser Guilherme II tentam roubar um submarino experimental da marinha britânica no Lago Ness. Finalmente, entre 1975 e 1977, o diretor Kevin Connor adapta três histórias fantásticas de Edgar Rice Burroughs, sendo que a segunda, At the Earth's Core, apresentava a Toupeira de Ferro, veículo metálico sobre esteiras com a parte frontal em forma de perfuradora, brutal por fora, elegante e sofisticado em seu interior, e no qual os protagonistas descem ao centro da Terra para encontrar o reino de Pellucidar.

Esta amostra, um tanto exaustiva, e provavelmente incompleta, é suficiente para mostrar que, a partir do marco inicial representado pelo Nautilus de Harper Goff em 1954, durante vinte e três anos a indústria cinematográfica explorou continuamente as imagens produzidas pelos escritores de fantasia e ficção científica de fins do século $X I X$ e início do século $X X$, Júlio Verne à frente. Estes filmes eram constantemente exibidos nos canais de televisão e povoaram a imaginação de milhares de pessoas. Quando, em fins da década de 1960 e início da década de 1970, começaram a ser publicados 
os primeiros romances que, mais tarde, viriam a ser considerados como proto-steampunk, já existia um substancial corpus fílmico evocativo das primeiras eras da ficção científica. Em 1979, quando K.W. Jeter publica o livro que, em conjunto com os romances de James Blaylock e Tim Powers, daria início ao subgênero steampunk propriamente dito, Nicholas Meyer produz o filme Time After Time, onde H.G. Wells é representado como o inventor da máquina do tempo e empreende uma viagem para o futuro (1979) para caçar Jack, o Estripador 6 .

As imagens produzidas pelas Voyages Extraordinaires e pelos scientific romances se replicaram e se perpetuaram, num movimento contínuo que passa pelo teatro e pela ópera, e são inseparáveis do cinema desde o seu surgimento, em mais de cem anos de releituras. Parece evidente que, quando K.W. Jeter escreveu sua famosa carta à revista Locus, em que ele, jocosamente, cunhou o termo steampunk para designar aquilo que ele então chamou de "fantasias vitorianas", e que, segundo ele, seriam a "próxima grande tendência", ele talvez não estivesse consciente de que estava apenas dando o próximo passo.

\section{REFERÊNCIAS}

ANGELIER, François (2012). Album Jules Verne. Paris: Gallimard.

BARTHES, Roland (2009). Mitologias. Rio de Janeiro: Difel. p.81-84 In http:// colemanzone.com/Time_Machine_Project/project.htm

EVANS, Arthur B (1999). "The Vehicular Utopias of Jules Verne”. In: SLUSSER, G.; ALKON, P.K.; GAILLARD, R.; e CHATELAIN, D. (Orgs.). Transformations of Utopia: Changing Views of the Perfect Society. Nova York: AMS Press. p.99-108. 
FRAZIER, Joel; HATHORNE, Harry (1984). “20.000 Leagues Under the Sea”. In Cinefantastique. 14(3), 32-52.

HANTKE, Steffen (1999). “Diference Engines and Other Infernal Devices: History According to Steampunk". In: Extrapolation: A Journal of Science Fiction and Fantasy, 40(3), 244-254.

KAEL, Pauline (1991). "The Deadly Invention". In: 5001 Nights at the Movies. New York: Henry Holt and Company. p.179.

KOVÁCS, Katherine Singer (1976). "Méliès and the "féerie'". In: Cinema Journal vol.16 n.1, University of Texas Press. p.1-13.

LO DUCA, Joseph-Marie (1952). “Georges Méliès, père du cinéma, fils de Jules Verne”. In: Cahiers du Cinema, n. 10. Paris: Les Editions de L'Etoile. p.52-53.

MOORE, Alan; O’NEILL, Kevin (1999). The League of Extraordinary Gentlemen, n.1-6. La Jolla, America's Best Comics.

NICHOLS, Peter. "Steampunk". In http://www.sf-encyclopedia.com/entry/ steampunk. Acesso em 28.Dez.2017.

PERSCHON, Mike Dieter (2012). The Steampunk Aesthetic: Technofantasies in a Neo-Victorian Retrofuture. Edmonton: University of Alberta.

PUISIEUX, Hélenè (1984). "Un voyage a travers I'histoire: une lecture sociale des films de Méliès". In: Méliès et la naissance du spectacle cinematographique. Paris: Klincksieck. p.25.

TAVARES, Braulio (2010). "Prefácio". In: WELLS, H.G. A máquina do tempo. Rio de Janeiro: Objetiva. p.7-13.

TAVES, Brian (1996). "Hollywood's Jules Verne". In: TAVES, Brian; MICHALUK, Stephen. The Jules Verne Encyclopedia. Methuen. Scarecrow Press. p.227.

TELOTTE, J.P. (2009). “Film, 1895-1950”. In: BOULD, M.; BUTLER, A. M.; ROBERTS, A.; VINT, S. (Eds). The Routledge Companion to Science Fiction. Abingdon. p.42-51. (2004). Science Fiction Film. Cambridge: Cambridge University Press. p.24.

TOULET, Emmanuelle (1988). O cinema, invenção do século. Objetiva. p.13; 61-62. VANDERMEER, Jeff; CHAMBERS, S.J. (2011). The Steampunk Bible. Nova York: Abrams Image. p.48. 